form ${ }_{A \wedge A D E M A M K}$

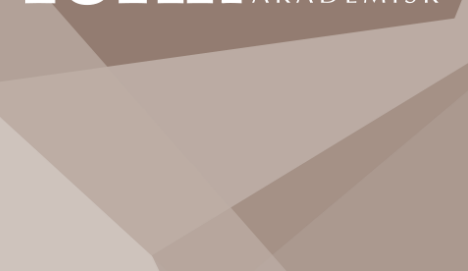

Vol I4, No I (202I)

\title{
Bilder i hjemmet - hvordan visuelle uttrykk definerer muslimske rom i Norge
}

\begin{abstract}
SAMMENDRAG
Målet for denne artikkelen er å undersøke hvordan norske muslimske familier orienterer seg mellom sunni-islamsk og vestlig visuell tradisjon, hvordan de forholder seg til dilemmaer som oppstår når tradisjoner divergerer, og hvordan de konstruerer sin visuelle og religiøse identitet når de lever i diaspora. Artikkelen baserer seg på empiri fra intervjuer med tjue unge informanter. De forklarer at de og deres familier klassifiserer bilder $i$ to hovedkategorier: Religiøse kalligrafiske bilder, som behandles i tråd med skikker og ritualer i hjemmet. Når det gjelder den andre kategorien, figurative bilder med sekulært fokus, er situasjonen annerledes: Noen typer av figurative bilder, særlig portrettfotografier, skaper konflikter i familiene. Innen sunni-islam finnes det ulike syn på slike bilder. Ofte blir portrettfotografiet oppfattet som en selvstendig sosial aktør, og man tenker seg at det kan øve uheldig innflytelse på betraktere og skape uro på de stedene der bønn praktiseres. Siden mange muslimer ber hjemme, kreves det nøye overveielser når bilder skal plasseres.
\end{abstract}

Nøkkelord:

visuell og religiøs identitet, sekulær-religiøs, organisasjon, diaspora

Doktorgradsprosjektet Taswir i norsk kontekst er en utforsking av hvordan unge norskpakistanske muslimer forholder seg til visuell kommunikasjon med figurative bildeuttrykk (Brekketo, 2013). Prosjektets empiri består av dybdeintervjuer med 20 ungdommer i slutten av tenårene. Informantene er anonymisert, og enkelte gjenkjennbare detaljer de beskriver fra hjemmemiljøet, er maskert. Så langt det er mulig, er intervjuenes muntlige preg beholdt, og ungdommenes egne språkuttrykk er prioritert. Innhenting av empiri ble utført etter retningslinjene til Den nasjonale komité for humaniora og samfunnsfag (NESH).

I samtalene gir ungdommene ofte uttrykk for at de lever i skjæringspunktet mellom ulike visuelle tradisjoner - nærmere bestemt forholder de seg aktivt til allmenn norsk praksis der figurative bilder er hyppig brukt i visuell kommunikasjon, men de eksponeres også for sunni-muslimsk praksis der det uttrykkes skepsis overfor figurative bildeuttrykk. 
En vesentlig del av prosjektet dreier seg om bruk av bilder i ungdommenes hjemmemiljø. De unge lever sammen med foreldre, og ofte også med besteforeldre. Dermed blir hjemmet et felles oppholdssted for personer med forskjellig alder og forskjellig oppvekst og bakgrunn. I samtalene kommer det frem at de som bor under samme tak, ofte responderer helt ulikt på bilder. Meninger formuleres og uttales, synspunkter brynes mot hverandre, og uenigheter kommer opp i dagen: Hva slags bilder som henges opp - og blir hengende - speiler styrkeforhold og interessemotsetninger innad i familiene.

I denne artikkelen går jeg tett på ungdommene og ber dem fortelle om bildene de har rundt seg til daglig. Blikket inn i deres hjem gir innsikt i hvordan en diaspora-situasjon fortoner seg i praksis. Rekken av hverdagens mange, og tilsynelatende små, valg reiser viktige spørsmål om identitet. Når familiene organiserer sine rom, og velger hvilke bilder de vil ha på veggene, forteller de seg selv og hverandre, men også besøkende, hvem de ønsker å være i en norsk samtidskontekst. De former moderne sunni-muslimsk identitet og skaper muslimske rom gjennom å uttrykke seg visuelt.

\section{METODEUTFORDRINGER}

En særlig utfordring i doktorgradsprosjektet Taswir i norsk kontekst (Brekketo, 2013) har vært å tilegne seg innsikt i en annen visuell tradisjon enn den vestlige. Ta for eksempel begrepet 'bilde' som er ladet med betydning fra en lang fartstid i kunsthistorien - som i sin tur er en forskningsdisiplin med dype røtter i europeisk tradisjon. Hva legger ungdommene i begrepet 'bilde'? Og hvordan kan en forsker bruke sin egen, vestlige bakgrunn på en fruktbar måte i møtet med nye forestillinger?

I fagmiljøer der det forskes på visuelle uttrykk har man erkjent behovet for å utvide horisontene. James Elkins har talt for å videreføre, men berike eksisterende terminologi med nye nyanser - blant annet for å sikre fellesskap og samforståelse mellom forskere (Elkins, 2007, s. 3-24). Andre forskere har hevdet at et utgangspunkt i eksisterende terminologi muligens ikke vil fremskaffe relevant kunnskap om tradisjoner som følger andre konvensjoner enn de europeiske. Enkelte forskere har $\emptyset$ nket å fremme nye begreper med forankring i miljøet som har frembrakt det visuelle studiematerialet (Kesner, 2007, s. 81-112). Et motargument mot denne siste strategien er at det visuelle fagfeltet vil bli så fragmentert at det ikke lenger har noe felles fundament.

Disse faglige diskusjonene peker mot metodiske utfordringer som foreløpig står uten gode Iøsninger. Jeg har valgt å bruke terminologi med forankring i vestlig tradisjon, også fordi ungdommene er oppvokst i Norge. For å kompensere for min manglende fortrolighet med islamsk tradisjon, har jeg fors $\varnothing k t$ å lytte oppmerksomt til ungdommenes beretninger, og å holde informasjonen om deres levde liv opp mot kunnskap jeg har tilegnet meg gjennom lesning. Derfor lar jeg for eksempel ungdommene selv definere hva de legger i begrepet 'bilde'. Men først noen ord om bildet som gjenstandskategori i vestlig forskning:

\section{BILDET - EN HELT SPESIELL GJENSTAND}

At mennesker knytter sin selvforståelse og sitt selvuttrykk til gjenstander, er godt kjent innen forskningen. I antropologi og religionsvitenskap har det vært forsket på betydningen av rituelle gjenstanders funksjoner i sosiale kontekster, mens fagfeltene materiell og visuell kultur i større grad har dreiet oppmerksomheten mot hverdagsgjenstander, og hvordan disse speiler identitet og intensjoner i moderne tid. Innenfor fagfeltet materiell kultur er det for eksempel gjort flere studier av hjemmets uttrykksregister. Studiene konsentreres om hvordan beboernes biografiske situasjon formidles gjennom innredningsvalg. Det kan for eksempel dreie seg om hvordan konsumholdning og bevissthet om gjenstanders symbolske kapital påvirker valg av innredning (Bourdieu, 1995; Rolness, 1995).

Innfallsvinkelen i denne artikkelen skiller seg noe fra generell gjenstands- og hjemforskning. Artikkelen handler først og fremst om bilder, og bilder har særegne trekk som gjenstandskategori: । bilder spilles det bevisst på visuelle virkemidler, og som oftest er kommunikasjonsaspektene spesielt fremtredende, mens andre aspekter ved gjenstanden, så som nytteaspektet, er nedtonet.

Fagfeltet visuell kultur har et begrepsapparat som er spesielt rettet mot visuelle mediers særegenheter, og gir et godt utgangspunkt for å drøfte denne artikkelens tema. I tillegg vil det være 
hensiktsmessig å trekke inn perspektiver fra fagfelt som antropologi og religionsvitenskap for å få grep om hvilke nyanser ved den religiøse dimensjon som uttrykkes visuelt i ungdommenes hjem.

I forskningen på det visuelle feltet har interessen tradisjonelt vært rettet mot bilders meningsformidling, det vil si mot hvordan bilder ved sin komposisjon kommuniserer idéer og forestillinger mellom avsender og betrakter. I løpet av de siste tiårene har det inntruffet et perspektivskifte i denne forskningen - et annet kommunikasjonsaspekt ved bilder er kommet mer i forgrunnen: Forskere retter oppmerksomheten mot hvordan bilder ved sin materielle tilstedeværelse virker inn på sosiale kontekster, og på betraktere og brukere av bilder (Gell, 1998; Freedberg, 1989; Didi-Huberman, 2005; Moxey, 2008, s.132-143; Rogan \& Naguib, 2011).

Mieke Bal, kulturteoretiker og fremtredende eksponent for fagfeltet visuell kultur, er for eksempel opptatt av å analysere det hun kaller "den visuelle hendelsen". Hun sikter da til hvordan bildet og dets visuelle omgivelser oppleves: På hvilke måter betrakteren bearbeider synsinntrykk og bringer dem i kontakt med andre persepsjonsinntrykk, og med kunnskaps- og erfaringsbakgrunn. Mieke Bal er opptatt av sammenhengene mellom fysiske bilder og mentale forestillingsprosesser, nærmere bestemt kognitive og følelsesbetonte prosesser. Disse individuelle bearbeidingsprosessene vil, ifølge Bal, også berøre større temaer, som forholdet mellom kunnskap og makt, slik dette forholdet kommer til uttrykk i sosialt og mellommenneskelige samliv (Bal, 2003, s. 9-11). Religionshistorikeren David Morgan tilbyr et supplerende perspektiv når han presiserer at visuell kultur også bør bidra til å unders $\varnothing$ ke hvordan bilder inngår i konstruksjonene av ulike virkelighetsoppfatninger (Morgan, 2005, s. 27, 32, 33; se dessuten Mitchell, 2003, s. 252; Mitchell, 2008/1995, s. 299, 307-308). Oppsummert kan man hevde at relasjonene som oppstår mellom bilde, betrakter og bruker står sentralt og har gitt retning til forskningen innen visuell kultur.

\section{UNGDOMMENES TANKER OM BILDEKATEGORIER}

Når ungdommene forteller fra sine hjem, understreker de at hjemmets oppgave er å danne ramme rundt svært forskjellige daglige aktiviteter. Blant annet må religiøs praksis, verdslige gjøremål og fritidssysler kunne finne sted. I samtalene snakker vi derfor mye om hvordan hjemmet er innrettet, og hvordan bilder plasseres i forhold til den livsutfoldelse som skjer i rommene.

Med henblikk på hvilke bilder som henger på veggene, trekker ungdommene raskt opp et skille mellom det de kaller religiøse bilder, og det de kaller verdslige bilder. Med religiøse bilder sikter de særlig til kalligrafikomposisjoner med tekster fra Koranen. Verdslige bilder omfatter figurative bilder med verdslige motiver, som for eksempel portrettfotografier. Dette er to bildekategorier som for ungdommene har vidt forskjellige funksjoner, og det er hensiktsmessig å gå nærmere inn på hver og en av dem.

\section{RELIGIØSE BILDERS REKKEVIDDE}

Allerede tidlig i samtalene blir det klart at de verdslige bildene ikke på noen måte plasseres tilfeldig omkring, de har ikke førsteprioritet: Selve rammeverket i innredningen utgjøres av de religiøse bildene og deres plassering.

Ungdommene forteller at disse bildene, særlig kalligrafikomposisjoner med tekster fra Koranen, har stor betydning i familiens dagligliv. De beskytter hjemmet og dets beboere. Her beskriver en av jentene, Halima, hvordan hun opplever virkningene av slike bilders tilstedeværelse:

Halima: [...] Samtidig har vi noen sånne vers og utskrifter fra Koranen, pent skrevet. Hengende for å trygge huset.

B: Trygge huset?

Halima: Trygge huset.

B: Fortell litt om det!

Halima: Altså trygge huset, for mange kan jo det være litt overtroisk, kanskje. Men det har vist seg opp gjennom religionen og tidene at de versene, de fire siste versene i Koranen, dem har veldig mye...ikke makt, men de har veldig mye energi i seg. Og det er for å holde seg unna det onde, da. 
Kalligrafikomposisjonenes tilstedeværelse oppfattes som en forsikring om at Guds gode innflytelse vil vedvare. Men flere av ungdommene antyder at bildene også har andre egenskaper, at de gir motivasjon og styrke i møte med utfordringer. En annen jente, Faiza, bringer dette på bane. Mens vi fortsatt snakker om bildenes beskyttende virkning, dreier Faiza samtalen mot ett spesielt bilde som betyr mye for henne personlig:

Faiza: [.....] Vi har et sånt lite vers, som vi alle pleier å lese. La oss si at jeg har en prøve......jeg mener at hver gang jeg leser det, så hjelper det meg veldig mye. Eller hvis jeg vil gjøre noe veldig bra, hvis jeg skal på intervju for å få jobb: Jeg føler at det går bra, for jeg fikk jobb...

$B$ : Gir den deg styrke?

Faiza: Ja, jeg fikk jobben nå, så jeg følte den kanskje hjalp meg. Før så var det ikke sånn. Jeg pleide ikke å gjøre det før, og da følte jeg at: "Herregud, det går jo rett i vasken!" Uansett hvor mye jeg forberedte meg. Nå, jeg forbereder meg, og leser den, så går det kjempebra.

B: Du tenker at den har en funksjon, ikke sant? Gir den deg en indre styrke, er det du...?

Faiza: Ja, det gir indre styrke, det motiverer meg, jeg tenker at jeg må bare lese den.

Faiza tror kalligrafikomposisjonen hjelper henne, men bare fordi hun gjør en egeninnsats. Hun forteller at hun uansett forbereder seg mentalt til den utfordringen som ligger foran henne. En del av forberedelsene er å lese verset på bildet. For Faiza fungerer bildet som et kontaktpunkt med guddommelige krefter utenfor henne selv. I de tilfellene Halima og Faiza beretter om, blir det tydelig at de religiøse bildene oppleves som aktører, som får innflytelse fordi betrakterne åpner for et mulig samspill.

En av guttene, Najib, er opptatt av et helt annet aspekt ved kalligrafikomposisjonene. For ham er det viktig at bildene signaliserer muslimsk identitet. Najib formulerer seg slik:

Najib: [...] Det symboliserer hjemmet, at det her er et muslimsk hjem. At det er muslimer som bor der, det er på en måte at man skal huske hvem man er, da. Hvordan din bakgrunn er, og hvor røttene dine kommer fra, og alt det der.

De religiøse bildene oppfattes som beskyttende, de motiverer til selvutvikling, de minner om tilhørighet og de signaliserer muslimsk identitet utad. I tillegg gir ungdommene uttrykk for at bildene inngår i en videre religiøs forestillingsverden. De forteller at hjemmets beboere forholder seg fysisk til bildenes tilstedeværelse på helt bestemte måter. I denne sammenheng bevirker bildene kollektivt utførte handlinger hos betrakterne.

Kalligrafikomposisjonene assosieres med Koranen. Ungdommene trekker paralleller mellom respektfull holdning overfor bildene og respektfull behandling av Koranen. Den hellige boken skal legges på en hylle høyt over gulvnivå, og tilsvarende skal kalligrafikomposisjonene plasseres høyt oppe på veggene. Najib forklarer:

Najib: Det blir akkurat det samme med skriften. Boken er boken. Men det er skriften som er innholdet. Og skriften skal ikke berøre bakken. Og når du tar ut skriften på et bilde, så kan du ikke la bildet være på bakken. Egentlig skal det være sånn.

Mange av de religiøse bildene henger på vegger som vender mot Ka'ba (islams ypperste helligdom) men en slik plassering er ikke gjennomført, selv om noen av ungdommene nevner at orienteringen mot Ka'ba er et poeng. Man vender ikke ryggen mot bildene, akkurat som man ikke vender ryggen mot Koranen:

Najib: Og vi vender ikke ryggen til Koranen. Eh, det gjør vi ikke.

$B$ : Dere vender ikke ryggen til Koranen?

Najib: Nei, det gjør vi aldri.

Ungdommene poengterer at bildene skal henge høyt fordi man må unngå å vende ryggen til dem. I tillegg nevner flere at man bør passe på å ikke peke med føttene mot bildene. Det er verdt å trekke frem et par eksempler. Asiya og Faiza uttrykker seg på følgende måte om bildenes nivå på veggen: 
Asiya: Ja, man bør i alle fall passe på at de ikke er såpass nede at hvis en person står, så vender ryggen mot bildet. Prøver å ha det i hvert fall over hodet, liksom. Og det er ikke alltid man får til det: Det finnes jo høye folk, altså! [ler].

$B$ : [ler].

Asiya: Men det pleier vi å passe egentlig på.

Faiza: [...] Men det som er, bildene må henge ganske høyt oppe. Det er en form for respekt, ikke sant, de skal henge høyt oppe, bare. Pluss at man skal ikke ha føttene mot bildene, og heller ikke mot Ka'ba.

Litt senere i samtalen utdyper Faiza, hun forteller at man hjemme hos henne har vært nøye med plasseringen av møblene i forhold til kalligrafikomposisjonene:

Faiza: Vi har satt sofaen sånn at vi ikke har føttene mot bildene.

Ungdommenes beretninger gir innblikk i en rekke forhold når det gjelder daglig omgang med det som betraktes som hellig. Alle i huset er svært klar over de religiøse bildenes plassering, og tar hensyn til dem. Møblenes plassering avpasses etter bildene for å forhindre at beboere og besøkende inntar stillinger som er uhøvelige.

Et viktig poeng ved de ulike respektfulle handlingene er at de synliggjør for alle i det sosiale rom hva som holdes hellig. Slike tydelige handlinger bidrar til dannelsen av en kollektiv enighet om hva som skal vises respekt og hvordan. Hver synlige handling styrker det helliges status samtidig som den bekrefter utøverens tilhørighet til gruppen.

Flere av ungdommene beskriver hvordan de er blitt innprentet at de ved å utføre ulike handlinger skal respektere og akte det hellige. Oppdragelsen har vært så konsekvent at handlingene til slutt utføres automatisk, enten det gjelder å styre føttene eller det gjelder å kysse en Koranbok som er falt ned. Ønsket atferd innprentes slik at den blir automatisert og kroppsliggjort, men også inderliggjort. Ungdommenes forhold til de religiøse bildene fremstår derfor ikke som utelukkende fysisk, men som forankret i følelseslivet (jamfør Ø $\varnothing$ stberg 2003, ss. 35, 49-50, 62; se dessuten Merleau-Ponty, 1986/1962, ss. 136-140, 185, 187, 198-199, 235).

Samspillet mellom bilder og beboere i hjemmet gir i høyeste grad uttrykk for en virkelighetsoppfatning der bildene åpner for religionens rekkevidde inn i alle livets forhold (jamfør Morgan, 2005, s. 27, 32, 33 om det visuelles innflytelse på virkelighetskonstruksjon). Bildene oppleves som operative på en positiv måte så sant beboerne møter dem med sensitivitet og respekt. Den visuelle hendelsen - for å bruke Mieke Bals begrep - som finner sted, er kompleks. Den omfatter ulike kommunikasjonsaspekter ved det religiøse bildet, så som formidling av meningsinnhold, formidling av symbolverdi, formidling av islams autoritet og direkte innflytelse i det sosiale rom. Det er verdt å merke seg at beboernes opplevelser av bildene i stor grad er samstemte: Uavhengig av deres ulike alder og ulike oppvekstvilkår er de enige om disse bildenes virkekrefter og status.

\section{DET VERDSLIGE BILDETS VIRKEKREFTER}

Det verdslige bildet, særlig det som har antropomorft motiv, regnes for å være et sterkt og virksomt medium, og det oppfattes forskjellig innenfor ulike kulturelle kontekster (Gell, 1998). I en vestlig kontekst lærer brukere og betraktere å opprettholde en rasjonell distanse til slike bilder, mens det $\mathrm{i}$ islam gjøres et poeng ut av disse bildenes aktøraspekt. De ulike innfallsvinklene angår denne artikkelens kjernetema siden ungdommene er fortrolig med begge tradisjoner.

I muslimske kretser foregår det en fortløpende diskusjon om det verdslige, antropomorfe bildet - en diskusjon som strekker seg langt tilbake i tid: Diskusjonsfeltet benevnes Taswir, som er arabisk for å gi gjenkjennelig form til en forestilling. Islamske lærde er opptatt av relasjonene som oppstår mellom antropomorfe bilder og mennesker. De har gransket religiøse kildeskrifter, og har bidratt til å utforme religiøse normer for bruk av slike bilder (Brekketo, 2014). I dag er det utviklet et bredt spekter av fortolkninger på Taswir-feltet, spesielt når det gjelder portrettfotografiet. Lærde trekker en forbindelse 
mellom fortid og nåtid: I begynnelsen spredte islams tilhengere den nye religionens abstrakte gudsbegrep ved å utføre symbolladede handlinger, som å jevne rivaliserende trosretningers gudebilder og gravbilder med jorden. Det antropomorfe bildet ble oppfattet som villedende, og ble i islams videre narrativ assosiert med hedendom (om motsetningene, nyansene og fortolkningene vedrørende figurativ fremstilling i islams tidligste æra, se blant annet Grabar, 2005, s. 43, 56; Grabar, 2006, s. 16; Mirza, 2005 , s. 414-426). Negative forestillinger hefter stadig ved antropomorfe bilder, idet man tenker seg at de forfører og blender med sin menneskelikhet. Islamske lærde hevder at det antropomorfe bildet er spesielt urovekkende siden det ved sin tilstedeværelse involverer betrakteren i en relasjon som kan oppleves å være gjensidig. I flere hadith-tekster advares det mot ansikters appell, og blikk ansees å være spesielt kontaktetablerende. I forlengelsen av dette resonnementet uttrykker noen lærde en særlig bekymring for avbildede ansiktstrekk, og anbefaler å utradere ansiktsdelen i bilder for å nøytralisere dets virkekrefter (Shakir, 1998, s. 72-73, 209; Al-Qaradawi, 2003/1960, s. 85, 92, 105; Grabar, 2005, s. 43; Gruber, 2009, s. 229, 236). Dette er synspunkter som særlig hevdes i konservative og fundamentalistiske fortolkningsmiljøer. De fleste lærde er i dag mer moderate, og mener at antropomorfe bilder kan gjøres uvirksomme dersom de dekkes til eller isoleres.

Videre ansees bildets plassering å være ladet med betydning. Dersom det antropomorfe bildet får en fremtredende plass, vekker det lettere positive følelser, som beundring. Spesielt er det viktig at bilder med antropomorfe motiver ikke plasseres i bønneretningen, siden en slik plassering gir inntrykk av at den bedende henvender seg til bildet. Dersom bildet derimot blir brukt til å sitte på (pute) eller trå på (teppe), mister det sine forførende virkekrefter fordi betrakterne ved sine handlinger demonstrerer at de ringeakter bildet.

Islamske lærde er altså særlig på vakt mot bilder med antropomorfe motiver dersom bildene inviterer til engasjement, beundring eller hengivenhet. Det viktigste argumentet mot bruk av bilder med mennesker som motiv, som for eksempel portrettfotografier, er at den sterke opplevelsen de gir betrakteren, kan representere et første steg på veien mot bildedyrkelse og polyteisme (shirk) (AlQaradawi, 2003/1960, s. 86-87; Mirza, 2005, s. 414).

I dag diskuteres først og fremst fotografiets bruksområder og dets virkninger på betraktere: । hvilke tilfeller er bruk av fotografi tilrådelig, betenkelig eller forbudt? Blant lærde finnes ulike svar på disse spørsmålene. Det er verdt å merke seg at selv om lærde målbærer forskjellige tolkninger, så er de alle opptatt av å begrense og kontrollere det antropomorfe bildets virkekrefter.

Både innen vestlig forskning og innen islamsk rettsvitenskap ( $f i q h$ ) står relasjonene mellom bilde og betrakter sentralt, men vurderingene av de relasjonene som oppstår, er svært forskjellige i disse to tradisjonene. Først og fremst finnes det en gradsforskjell i beskrivelsene av hvor operativt et antropomorft bilde kan tenkes å være gjennom sin tilstedeværelse.

I det empiriske materialet er det er påfallende hvor samkjørte ungdommene er når de plasserer bilder i religiøse og verdslige kategorier, og, ikke helt uventet, skilles de antropomorfe bildene ut som en egen, potensielt problematisk, kategori - helt i samsvar med tankegodset fra taswir-diskusjonene.

\section{BILDER OG BøNN}

Det viser seg at portrettfotografier er en særlig kilde til uenigheter i familiene. Alle er i besittelse av slike bilder, men hvordan de skal plasseres, og hvordan deres virkekrefter kan kontrolleres, er et aktuelt og omdiskutert tema i flere av familiene.

Alle familiene praktiserer bønn i hjemmet. Uten unntak forteller ungdommene om hvor viktig det er å skjerme seg for hverdagslige distraksjonsmomenter under bønnen. I islam trekkes det ikke noe prinsipielt skille mellom sekulært og hellig rom, religionen skal ideelt sett kunne praktiseres overalt. Denne idéen om at rommet skifter karakter etter handlingene som finner sted, får konsekvenser for avveiningen mellom religiøse og verdslige bilder. Mange strever med å finne en tilfredsstillende ordning når det gjelder å kombinere bønn med nærværet av verdslige antropomorfe bilder. Det er særlig de nevnte portrettfotografiene som skaper utfordringer. Familienes strategier er forskjellige. I det følgende får flere av ungdommene selv utdype hvordan bilder og bønn forholdes til hverandre hjemme hos dem. 
Maira forteller at en av utfordringene når man skal be hjemme, er tilstedeværelse av portrettfotografier. Hennes familie har valgt en løsning der et eget rom reserveres for slike verdslige bilder, musikkanlegg, musikkinstrumenter og leker. I dette rommet kan man traktere instrumenter selv, lytte til musikk eller henge opp bilder av artister man liker. Maira nevner flere ganger at verdslige bilder og musikk står i en særstilling fordi mange muslimer assosierer disse kunstuttrykkene med en verdslig livsstil. Hun understreker at det derfor er en god ordning å ha alt som relaterer til verdslige figurative bilder og musikk i et eget rom atskilt fra religionsut $\varnothing$ velsen.

Å skjerme religiøs praksis fra verdslige figurative bilders nærvær er en utfordring også hjemme hos Najib, men hans familie har valgt å innrette seg annerledes enn Mairas familie. Najibs familie har innredet et eget rom for bønn. Der inne finnes bare religiøse bilder:

Najib: [...] Så vi har et eget rom som vi har separert, ved siden av stua. Med en gang du åpner rommet, så er det: Vi har det veldig pynta der hele tida. Mamma har pynta. Du har kanskje over tretti bilder. Bare i det ene rommet. Masse forskjellig arabisk.

$B$ : For da er det bare de hellige bildene?

Najib: Ja. Riktig.

$B$ : Går jeg ut fra?

Ikke alle har anledning til å innrede separate rom for religiøse eller verdslige aktiviteter. For mange er det et spørsmål både om plass og romplan. Flere av ungdommene forteller at en vanlig løsning er å henge verdslige og religiøse bilder på forskjellige vegger. Fatima forteller:

Fatima: For eksempel hvis det er to vegger, så henger kanskje de religiøse her, og så ligger det noen portrettbilder av familien [viser med hendene en viss avstand].

$B$ : Akkurat.

Fatima: Det kan være på lik høyde, bare det helst ikke henger ved siden av.

$B$ : Men hvordan er det da gjort hjemme hos deg? Er det en avstand der?

Fatima: Det er ikke noen spesiell avstand, men det som er: På den ene veggen er det for eksempel bilde av meg og søstera mi som liten, og på den andre så er det sitater fra Koranen.

$B$ : Ja, så dere har valgt å faktisk skille dem fra hverandre, da?

Fatima: Mm.

Bilal forteller at dersom det er verdslige figurative bilder i rommet, dekkes disse til ved bønn:

Bilal: [...]...så tar man det bort, eller så kaster man et pledd over dem eller noe sånt. Og noen fortalte meg det at de gjør det fordi når du ber, så skal du være fokusert for at du skal kommunisere med Gud, ikke sant? Og når det er bilder der, kan du bli distrahert. Så det er derfor de gjør det.

Andre lar bildene henge der de henger og utvikler mentale strategier for å overse dem. Gori forteller at de hjemme hos ham har et verdslig figurativt bilde som henger på den veggen som vender mot Mekka:

B: Men hvis man ber hjemme og sånn, da. Så har jeg hørt at man ikke kan ha bilder på veggen, som forestiller noe.

Gori: Jeg har også hørt det, men det bildet som jeg fortalte deg om i stad, der hvor hun jenta sitter ved brønnen...

$B$ : Ja?

Gori: Det er liksom rett foran der faren min pleier å be. Fordi det er sånn at du skal ikke be til den sida eller den sida, du skal be mot Mekka. Det er noe sånt.

$B$ : Ja?

Gori: Så hjemme hos meg når du ber mot Mekka, så er det bildet foran deg.

B: Jaha?

[...]

Gori: Ja. Fordi faren min tenker at han ber til Allah, han ber ikke til det bildet der, liksom.

$B$ : Nei, skjønner.

Gori: Så da er det like greit å ha et bilde der når du ikke tenker på det bildet og ikke ser på det en gang. 
$B$ : Det er det som er viktig?

Gori: Ja, det er det som er viktig. Når vi skal be, så ber vi til Allah, vi skal jo ikke be til det bildet der. Hvis jeg står foran, det gjør ikke meg noe. Og hvis det ikke hadde vært der, så hadde det kanskje ikke gjort noe det, heller.

$B$ : Nei, nettopp. Det er hvor man plasserer oppmerksomheten sin som er viktig, er vel det du forteller meg nå, ikke sant?

Gori: Ja. Jeg føler det sånn. [...]

I dette utsnittet snakker Gori om at faren styrer konsentrasjonen dit den bør være. Og han bedyrer at det verdslige figurative bildet, som henger i bønneretningen, ikke gjør noe inntrykk på ham selv heller under bønn. Allikevel medgir han at det kanskje hadde vært enda bedre dersom bildet ikke hadde vært der, for det foresvever ham at det finnes religiøse retningslinjer som angår slike bilders plassering under bønn. Til syvende og sist stoler han mest på sin egen følelse. Han ser ikke noen risiko for bildedyrkelse eller polyteisme så lenge bildet ikke engasjerer eller distraherer dem som ber. For Gori og hans familie er ikke verdslige figurative bilder noen stor sak. For ham avhenger konsentrasjonen av disiplin på det mentale plan, ikke av visuelt rolige omgivelser.

Familiene velger altså ulike måter å organisere hjemmet på, og alle er opptatt av de verdslige figurative bildenes potensielt uheldige virkekrefter under bønn. Her slår forestillingene fra taswirdiskusjonene inn med autoritet. Fortellingene fra ungdommenes hjem røper at religionsut $\varnothing$ velsen har høy prioritet i dagliglivet, men at praktiske hensyn allikevel trumfer de helt ideelle hensyn om religionens allestedsnærværelse: Religionen praktiseres ikke hvor som helst i hjemmet når bønnetiden inntreffer, det inngås kompromisser slik at ulike soner er opprettet for ulike gjøremål. De som har knapphet på plass, er omhyggelige med å dekke til verdslige figurative bilder under bønn. Beretningen fra Goris hjem, der de under bønn bruker mentale distanseringsstrategier, er enestående i dette empiriske materialet.

\section{KJØNNSSEGREGERING}

I de videre samtalene viser det seg at det er enda flere hensyn å ta når det gjelder plasseringen av verdslige figurative bilder, og da snakker ungdommene særlig om portrettfotografier.

Sidra forteller at fotografier av kvinner og menn plasseres i forskjellige rom hjemme hos henne. Bildene av mennene og guttene henger i oppholdsrommene, mens bildene av kvinnene og jentene henger $\mathrm{i}$ det hun kaller de private rommene - det vil si soverommene. Sidra beretter om episoder dersom hun eller søsteren $\emptyset$ nsker å ha sine portrettbilder i stua. Da griper bestemoren raskt inn:

Sidra: Ja, eller i kulturen vår er gutter ganske frie, og det har du sikkert skjønt?

$B$ : Ja da. Det har jeg skjønt! [ler].

$[\ldots]$

Sidra: Ja, og da er det greit at bilder av brødrene henger der, eller faren min. Eller moren min til og med, for hun er gift kvinne. Men hvis det er bilde av meg og søstera mi, da er hun [bestemoren] litt sånn skeptisk og: "Nei, bare ta ned! Hvorfor skal de være der?" Hun sier aldri årsaken rett ut. Hvis jeg spør mamma om hvorfor hun sier det, så forklarer hun meg: "Hun vil ikke at dere skal henge der fordi dere er single jenter, og hvis det kommer gutter, så mener hun at de ser på dere."

$B$ : Hun vil på en måte skjerme de jentene som ikke er gift enda?

Sidra: Ja.

$B:[\ldots]$...går det på generasjon, forresten? Tror du det?

Sidra: Ja, det gjør jo det.

Portrettene av familiens mannlige medlemmer henger i oppholdsrommene. Sidra forteller at morens portrett også kunne hengt der fordi hun er gift. En viktig distinksjon når det gjelder bildeeksponering går ifølge Sidra mellom gift og ugift kvinne. Når et portrettfotografi henger på veggen, er den avbildede vedvarende eksponert og utsatt for betrakteres granskende, begjærlige eller fabulerende blikk. Grunnen til at portrettfotografier av unge ugifte kvinner ikke henger i oppholdsrommene, er et ønske om å skjerme dem for oppmerksomhet, men også et ønske om å kontrollere betrakterrollen. Det er særlig Sidras bestemor som er nøye med bildeplasseringen, og Sidra mener at generasjonene forholder 
seg forskjellig til slike bilder. Selv forklarer Sidra bildeplasseringen hjemme med at gutter og menn er friere enn jenter og kvinner i hennes miljø. Det aner meg at hun kanskje har følt at de definerte kjønnsrollene har begrenset hennes utfoldelsesmuligheter, og jeg forsøker å finne ut mer om hvordan hun tenker:

B: Men hvordan ser du på disse tingene, ikke sant? For dette er miljøet rundt deg, men er du enig i dette, eller er du uenig i det? Kunne du tenke deg å bruke bilder på andre måter?

Sidra: For meg er det egentlig det samme. Jeg kan godt ha bilder av personer eller....jeg har jo sagt til mamma at: "Ha bilde av meg i stua!" Sånn stort bilde av meg. [ler]. Det var et veldig pent bilde, og hun var sånn: "Ja, det kan vi godt gjøre." Og pappa var til og med: "Ja, greit." Og så sier han etterpå: "Neeei, det er jo litt sånn alene bilde av deg i stort i stua vår, og så kommer jo folk og setter seg. Nei, ta det på rommet ditt, da." De sier aldri direkte årsaken til at det ikke kan være av meg der. Men de går rundt der på en måte, det samme som bestemor sier på en måte. [...] ...de sier aldri ting direkte. Og jeg tror det er fordi jeg er jente.

Sidra gir uttrykk for at hun godt kunne tenke seg å henge opp et portrettfotografi av seg selv i stua. Hun ser ikke noe unaturlig ved en slik plassering. Hun har til og med gjort konkrete fremstøt for å få opp et bilde. Hun har utfordret bestemorens holdninger, men er blitt avvist. Sidra gir uttrykk for at hun føler seg forskjellsbehandlet fordi hun er jente. Hvor foreldrene står i spørsmålet om bildeplassering, er ikke enkelt å utlede fra det som sies. I Sidras fortelling fremstår foreldrene som unnvikende, kanskje litt brydde, når de kommer i klem mellom ulike familiemedlemmers ønsker og krav. De fører en balansegang der de manøvrerer mellom en eldre og en yngre generasjons uttrykksbehov i samme hjem.

Faiza har også opplevd motstand da hun ville henge opp et portrettbilde av seg selv i et av oppholdsrommene i leiligheten. Her forteller hun om det som nettopp er skjedd:

Faiza: [...] Men faktisk, jeg snakka med mamma for noen dager siden. Hun henta noen sånne rammer. Så sa jeg til henne: "Vi er to søstre. Kan ikke du sette et bilde av oss i hver av dem og henge dem opp i stua?" Men da blanda hun faktisk inn det med islam, hun blanda inn det at hun ikke vil at når menn kommer, at hun ikke vil at de skal se oss sånn.

$B: \AA$, ja?

Faiza: Da blanda hun inn en litt annen ting, ikke sant? Hun bare: "Jeg liker ikke at vi henger opp sånne bilder. Og så kommer menn, og så kommer guttene deres, og så ser de på dere." Hun likte det ikke. Men jeg synes det er fint, for jeg likte de rammene. Så jeg sa: "Ok, hva med i gangen?" Hun bare: "Nei, der også, det er det samma." Jeg bare: "Men de oppholder seg ikke like lenge i gangen som i stua. I stua kan de sitte og se på, men i gangen er det sånn at de legger merke til det, men så går de." Hun bare: "Vi får se." Men hun ville ha det i kjøkkenet, da, for der tenkte hun, der er det mest kvinner. Men tanken er jo der enten det er mann eller kvinne som ser deg, de ser deg uansett. Så hvorfor har du den forskjellen? Men hun sa: "Vi får se." Men jeg tror ikke hun gidder å henge dem i stua.

I denne beretningen trer Faizas mor frem som den myndige personen i familien. Også hun er tilbakeholdende med å gi tillatelse til å henge opp portrettfotografier av døtrene i oppholdsrommene. Fortellingen gir ikke utsikt til flere voksne i familien, eller til samspillet mellom flere generasjoner enn mor og datter. Det er derfor uvisst hvorvidt moren tar hensyn til ulike behov i familien når hun setter foten ned for fotografier. Men hun gir religiøse begrunnelser for sitt standpunkt, noe Faiza synes å oppfatte som usaklig.

Bakgrunnen for morens motstand er nok at hun ønsker å kontrollere hvordan døtrene blir eksponert for menns blikk. Ved å velge plassering av bildene kan moren regulere både i hvilke situasjoner og for hvor lang tid av gangen de avbildede blir utsatt for oppmerksomhet. Moren foreslår en plassering på kjøkkenet der bildene vil bli sett, men av kvinner. Faiza er pågående, hun forhandler om andre plasseringer av bildene. Hun foreslår gangen, der husets gjester av begge kjønn passerer, men der bildenes eksponeringstid vil være kortere enn i stua. Faiza forstår godt poenget med å regulere bildenes eksponeringstid, men hun er ikke villig til å godta det hun oppfatter som forskjellsbehandling av kjønnene. Hun mener at fotografier inviterer til observasjon uansett, og uavhengig av hvordan rollene 
som betrakter og avbildet fordeles mellom kjønnene. Faiza tenker seg at vekslingen mellom subjekt- og objektposisjoner bør kunne skje friere, og ikke være underlagt sosialt konstruerte forordninger.

I samtalene er det først og fremst jenter som har tatt opp temaet kjønnssegregering når det gjelder bildeplassering. Dette er antakelig ikke tilfeldig, siden de jentene det gjelder, har opplevd at konvensjoner har henvist dem til en kjønnsrolle som ikke rimer med deres selvoppfattelse.

I samtalene kommer det frem at tanken om kjønnssegregerende bildeplassering virker fremmedartet for ungdommene som forteller. Bare tre av de 20 intervjuede ungdommene tar opp dette temaet på eget initiativ, men flere bekrefter at en slik praksis forekommer.

Faizas mor synes å begrunne kjønnssegregerende bildepraksis med islamske argumenter, men hvorvidt det dreier seg om religiøs eller kulturell begrunnelse, er et spørsmål med komplisert svar. Skjerming av kvinneportretter er et tema i taswir-diskusjonene, der ønsket om diskresjon særlig målbæres av konservative og fundamentalistiske lærde. Én av guttene i empiri-materialet trekker opp sammenhengen mellom kjønnssegregerende bildeplassering og bekledning med hijab (arabisk for "forheng, gardin, skille"). Historisk sett har slørbruk og kjønnssegregering vært nært forbundet i islamsk praksis. Hijab har blant annet vært et middel for å begrense kontakten mellom kjønnene, og ble tidlig assosiert med renhetsforestillinger (Vogt, 2004, s. 23-36; Thorbjørnsrud, 2004, s. 51; Jacobsen, 2006, s. 73-283; Se også purdah, Aase, 1997, s. 154; Østberg, 2003, s. 36, 41; Qureshi, 1996. s. 52; Naguib, 2002, s. $162-$ 163). Kjønnssegregerende praksiser skal ha sitt opphav i før-islamske samfunn, og dermed blir det et skjønnsspørsmål hvorvidt man velger å spore dem tilbake til ikke-religiøse skikker, eller hvorvidt de betraktes som integrerte deler av islam.

Ungdommenes beretninger har uansett vist at portrettfotografiets virkekrefter tenkes å slå to veier: Ikke bare har det virkning på betrakteren, det virker også utleverende for den som avbildes. Dette siste momentet blir, som vi ser, tillagt stor vekt i noen familier der det fortløpende utveksles meninger om hvorvidt familiemedlemmer b $\varnothing$ r utsettes for slik eksponering. De bekymringene som ungdommene refererer til når det gjelder portrettfotografier, rimer godt overens med de mest sentrale argumentene mot antropomorfe bilder i taswir-diskusjonene, der lærde fremholder at opplevelse av kontakt med den avbildede engasjerer betrakteren og inspirerer til holdninger som har valør av bildedyrkelse og polyteisme.

\section{MER OM PORTRETTFOTOGRAFIERS PLASSERING}

Flere av ungdommene forteller at det finnes motforestillinger mot $\mathrm{i}$ det hele tatt å henge portrettfotografier på veggene. I samtale med Hussain støter jeg på forestillinger om at portrettfotografienes virkekrefter absolutt bør nedtones i rommene:

B: Men da oppsummerer jeg: Fotografier av familie, som mange har på veggen, har dere det, eller har dere ikke det?

Hussain: Vi har album de ligger i.

B: Album de ligger i, ja?

Hussain: Ja. For vi henger dem ikke opp.

$B$ : Nei.

Hussain: Og så henger det et lite bilde av meg på kjøkkenet, da. Et lite bilde. Det er ikke noe sånt stort ...

$B$ : På kjøkkenet?

Hussain: Ja. Slik at ikke alle ser det.

$B$ : Er det et poeng? At ikke alle skal se det?

Hussain: Ja, de som kommer hjem til oss, de klager på det.

$B$ : Men du, hvem er det? Er det vanlige folk, eller er det folk med religiøs bakgrunn?

Hussain: Religiøs bakgrunn. De med skjegg og ... imamer og sånt, da. Det er ikke så ofte de pleier å komme, men de passer veldig på det.

I den neste samtalepassasjen innleder jeg med å oppsummere det Hussain har gitt uttrykk for så langt:

B: Men det er ikke du som bestemmer på fellesområdene? 
Hussain: Nei. Det går ikke. Siden der kommer det familie og besteforeldre og sånn. [...] ...når de eldre sier noe, så må vi følge det dem sier. Du kan ikke diskutere det dem sier. Det går ikke, eller, jeg vet ikke, det er ikke sånn i min familie i alle fall.

$B$ : Men er det sånn at det er de eldre som bestemmer hvilke bilder som henger oppe, for eksempel i stua?

Hussain: Ja.

$B:[\ldots]$...Har det vært en diskusjon om hvilke bilder som skal være til stede eller ikke i familien? Hussain: Egentlig ikke. Men da de var her, besteforeldrene mine, det er dem som sa det: At dere må fjerne dem. Det er ikke så veldig bra å ha det. Siden det står i Koranen. Og så, da får man gjøre det, da.

I Hussains nære miljø finnes krefter som øver press for å få gjennomført en fjerning av fotografiene fra veggene. Antropomorfe bilder skal ikke ha en iøynefallende plassering, men kan tolereres dersom de oppbevares i album. Hussain står i opposisjon til disse kreftene, og markerer sitt standpunkt diskret med et lite portrettfotografi av seg selv på kjøkkenet. I dette tilfellet kommer ikke presset om å fjerne bilder fra hjemmets beboere, men fra besøkende slektninger. Man må kunne anta at Hussain ikke er alene om å yte en viss motstand. At det lille portrettfotografiet blir hengende, betyr antakelig at han har støtte fra andre av hjemmets beboere. Allikevel er det sosiale presset utenfra såpass sterkt at familiens fotografier stort sett befinner seg i album. Hussains beretning er ikke noe særtilfelle. I flere av familiene er en stor del av portrettfotografiene oppvart i album, eller de ligger bortgjemt i seksjonene.

\section{ANTROPOMORFE BILDER PÅ UNGDOMMENES ROM}

Meningspluralismen og fornemmelsen av generasjonsskiller kommer særlig til syne der hjemmets beboere ikke kan enes om plassering av portrettfotografier. På sine egne rom mener ungdommene at de $b \emptyset r$ ha friere valg, men også her merkes spenningene i synspunkter. Jeg fortsetter å lytte til Hussain der han flytter oppmerksomheten fra hjemmets fellesområder til sitt eget rom:

Hussain: [...] Og så har vi bilder av, det er ikke noen bilder av dyr eller mennesker, siden det står i Koranen at det ikke er tillatt å ha det. Da kommer ikke akkurat englene til deg. Vi følger den regelen, egentlig.

$B$ : Dere følger den regelen?

Hussain: Ja. Men på rommet mitt har jeg litt andre bilder, av mennesker. Som jeg ser opp til eller liker.

Og litt senere slår han fast:

Hussain: Så jeg har siste ordet på rommet mitt. Eller, det er jeg som bestemmer der.

Hussains beretning er representativ for flere av ungdommene som har deltatt i unders $\varnothing$ kelsen. De fleste mener at de ikke har avgjørende innflytelse når det gjelder bildevalg på fellesområdene, men på sine egne rom vil de bestemme selv.

Det er et faktum at de fleste ungdommene har hengt opp antropomorfe bilder på rommene sine, og de føler seg komfortable med det. Selv om de unge synes det er rimelig at de bestemmer på sitt eget rom, er flere av dem vare for foreldrenes meninger om bilder. Noen av guttene er opptatt av å holde seg innenfor de grensene foreldrene aksepterer når det gjelder valg av bildemotiver. På spørsmål om hvilke grenser som ikke må overskrides, nevner de raskt at bilder av nakenhet er tabubelagt.

$B$ : Men andre bilder, har det vært noen diskusjoner?

Omar: Nei, det har aldri vært noen diskusjoner. Fordi, de vi henger opp, vi vet liksom hva vi henger opp.

Vi tenker jo langsiktig, om det er greit for foreldrene våre.

B: Hva sa du nå?

Omar: Vi tenker jo på om det er greit for foreldrene våre før vi henger dem opp.

$B: \AA$ ja? Ok.

Omar: Vanligvis, vi pleier å spørre. Om det er greit. 
$B$ : Dere tenker på hva foreldrene vil synes. Hva slags forestillinger har du om det: Hva er det du for eksempel kunne tenke deg å henge opp som foreldrene ikke ville like?

Omar: Nakne damer, for eksempel.

$B$ : Så det har vært litt interesse for å henge opp det, da?

Omar: Hadde ikke vært farlig for meg, liksom. Men vi må tenke på foreldrene våre også.

$B$ : Men da vet du at du får nei, da?

Omar: Ja, så det er ikke vits i å prøve.

Omar respekterer foreldrenes grenser enten han er personlig enig i disse grensene eller ikke. Her er det snakk om bildemotiver, men det finnes eksempler på foreldre som gjerne skulle sett at det antropomorfe bildet som sjanger ikke fantes på ungdommenes rom i det hele tatt. Hussain refererer til reelle hendelser og diskusjoner når han forteller om forskjellen mellom sin egen prinsipielle holdning og andre familiemedlemmers prinsipielle holdning til antropomorfe bilder:

B: Men det at du velger å ha bilder på veggen, det synes foreldrene dine er helt ok? Hussain: Det var en liten diskusjon på det først. Så sa jeg at det er mitt rom, jeg bestemmer. Og så ble det stille, men de liker det ikke fortsatt.

$B$ : De ble stille? De måtte respektere det?

Hussain: Ja. De liker det ikke fortsatt, at jeg har bilder av mennesker.

Når Hussain først har vist seg ubøyelig og valgt antropomorfe bilder, begynner diskusjonene om motiver. Han forteller at han tidligere hadde hengt opp et bilde som overskred grensen ved nakenhet, om enn på en humoristisk måte. Reaksjonene uteble ikke:

Hussain: Det var en liten stund jeg hang opp et bilde. [...]

Som det var en dame på, da. På rommet mitt. Og mamma ble veldig sur på meg på grunn av det. Det var en naken dame, da. Det var et morsomt bilde, jeg så hun begynte å le. Men bare: "Hva skjer hvis de eldre ser det?" Jeg tror mamma hadde sagt at det er greit, men hvis bestefaren og bestemoren kommer hjem hos oss ... De kommer ganske ofte. På to uker så kommer de kanskje to ganger eller noe sånt. $B$ : Ja, da blir det mye opp og ned med bilder! [ler].

Utfra beskrivelsen er det vanskelig å avgjøre hva slags bilde Hussain snakker om, men han presiserer at det var en humoristisk motivbehandling. Morens reaksjon, det at hun måtte beherske seg for ikke å le, tyder heller ikke på at bildet virket støtende.

Morens bekymring var heller at de eldre skulle komme til å se bildet, og at de ikke ville tolerere det. I dette tilfellet handlet morens motstand mot bildet om ubehaget ved å bli moralsk vurdert ut fra bildevalg. Den situasjonen Hussain beskriver tyder på at foreldre av og til inntar meklerrollen mellom familiemedlemmer når det gjelder bruk av bilder. Hussain, på sin side, forteller at han forhandler med utholdenhet for å oppnå uinnskrenket råderett over rommet sitt.

Kani forteller om prinsipielle bildediskusjoner med foreldrene. Moren hans likte ikke at han ville henge opp bilder av fotballspillere:

Kani: Ja. Det var diskusjon da jeg var yngre. Jeg ville ha bilder av fotballspillere. Og da sa mamma at jeg ikke burde ha det. Men etter hvert sa hun at: "Det er opp til deg." Det beste er å ... enten så har du ikke noen bilder, eller så har du bilder, men da skal de være religiøse.

B: Ja, nå begynner du å komme inn på noe: Da var hun litt streng på det, da? Hva kan det være hun mente ikke var bra med å ha bilder? Av fotballspillere på rommet?

Kani: Det jeg tror, er at hun ville ikke at jeg skulle glemme religionen min. Tror jeg i hvert fall. Men jeg har alltid hatt den i bakhodet. Men så er det jo det at det er ikke lov å ha bilder, av nakne modeller og sånt, da. Så hun var litt streng på det.

$B$ : Men nakne modeller, det er jo én ting. Påkledde modeller, ...altså de fotballfolka var vel påkledd? Kani: Ja, ja, ja!

$B$ : Men de var ikke helt bra, mente hun da? Og de kunne få deg til å glemme religionen? Men det er du ikke enig i? For du har den i bakhodet, som du sier?

Kani: Ja. 
$B:$ Og etter hvert så får du gjøre som du vil?

Kani: Men det er jo litt annerledes, siden vi bor i Norge. Det er litt mer frihet.

Kani opplever at han får veiledning, ikke påbud. Han får høre at det beste er å unngå verdslige bilder, men at han gjerne må velge religiøse bilder. Av samtalekonteksten går det frem at motstanden mot verdslige antropomorfe bilder er religiøst begrunnet. Kani har i alle fall tolket morens bildemotstand som engstelse for at religionen skal komme i annen rekke. Moren gir Kani rom for å treffe egne valg, han ansvarliggjøres i forhold til sine prioriteringer. En grunnleggende tanke $\mathrm{i}$ islam er at barnets egenansvar øker med religiøs opplæring, ervervet kunnskap og modning (jamfør forestillingen om at et menneske blir religiøst ansvarlig for sine handlinger i løpet av puberteten, når det har fått fullt utviklede åndsevner (mukallaf) (Ramadan, 2004/1999, s. 91). Kani forteller at han alltid har hatt religionen i bakhodet, noe som vitner om at han aktivt vurderer sine valg opp mot en moralsk standard han har satt for seg selv. I den litt mer springende delen av samtalepassasjen, mot slutten, poengterer Kani at han oppfatter det norske oppvekstmiljøet som mindre konformt enn det pakistanske miljøet han kjenner. Forskjeller mellom norske og pakistanske forhold er noe som opptar ham, og som han kommer tilbake til flere ganger i løpet av samtalen. I akkurat dette tilfellet er det usikkert hva han sikter til, men i lys av samtalens helhet er det sannsynlig at han opplever at det er mindre sosialt press og større rom for individuelle valg i Norge. Alt i alt, slik Kani presenterer sin historie, virker han tilfreds med den råderetten han har over hva som henges opp på rommet. Men det er likevel ingen tvil om at beretningen hans peker mot en reell uoverensstemmelse som finnes mellom ham og moren når det gjelder holdninger til antropomorfe bilder.

Amina skiller seg ut i det empiriske materialet, og nettopp derfor er det viktig å høre hennes beretning. Amina har tenkt nøye over hva hun vil kommunisere om seg selv gjennom en fotocollage fra russetiden der hennes selvportrett har en sentral plass. Hun er opptatt av kreativitet, av individualitet og av folks respons på portrettene av henne. Beretningen hennes handler om hvordan hun veksler mellom avsender- og betrakterposisjon mens hun vurderer hvordan bildecollagen vil virke. I løpet av samtalen skildrer Amina også seg selv som person. Hun har en seriøs innstilling til skolearbeid, og det som hun er mest usikker på når det gjelder collagen, er om denne egenskapen kommer til uttrykk. Beskrivelsene av den visuelle komposisjonen av russebildene røper at Amina er bevisst på hvordan hun vil fremstå for seg selv og for andre. Hun iscenesetter seg selv, et fenomen som er fremtredende i senmoderne samfunnskontekster. Vel er Amina opptatt av iscenesettelse, men hun er også opptatt av ekthet: Hun ønsker å oppnå at de visuelle virkemidlene hun velger, formidler hennes egen selvoppfattelse til betraktere.

I tillegg presiserer Amina at russebildene er en mulighet til å dokumentere et stadium i hennes identitetsutvikling, en måte å gjøre opp status på:

Amina: Fordi det er bare sånn symbol på hvem jeg var på den tiden, ikke sant? For folk utvikler seg jo hele tiden! Jeg er jo ikke den personen jeg pleide å være for ti år tilbake. Og jeg vil bare på en måte fryse det $\varnothing$ yeblikket sånn at jeg vet at ungdomsskolen, videregående det var da en opplevelse for meg. Jeg møtte nye mennesker. Og dette var de minnene jeg har hatt fra det $\varnothing$ yeblikket.

$B$ : Avsluttet en periode?

Amina: Ja. For å fortsette videre. Så det er grunnen til at jeg ønsker å ha det av meg, da.

Her berører Amina særtrekkene ved fotografiet som medium. Hun fremhever fotografiets evne til å fryse et фyeblikk og holde det tilgjengelig for inspeksjon i ettertid. Videre kobler hun fotografiet til identitetskonstruksjon. Hennes forestillinger om identitet rimer med senmoderne definisjoner der identitet beskrives som fortløpende selvrefleksive prosesser (Giddens, 1997, s. 11-12; Ziehe, 1989, s. 66-67). Amina erkjenner at hun er i stadig endring. Fotografiet synes å representere en oppsummering av fortiden som hjelper henne å stake ut retningen for fremtiden. I så fall fungerer fotografiet som et referansepunkt for nyorientering. Det metaperspektiv som Amina anlegger på den visuelle kommunikasjonssituasjonen, og den måten hun forholder seg til antropomorfe bilder på, er velkjent i norsk og vestlig tradisjonskontekst, men ikke særlig uttalt i islamsk kontekst, og den er helt fraværende i taswir-diskusjonene. 
Det samlede inntrykket fra samtalene er at bildemotiver skaper diskusjoner i noen tilfeller, men at foreldrene sjelden fors $\emptyset$ ker å håndheve noe prinsipielt forbud mot verdslige figurative bilder. En slik tendens vil i så fall være i takt med utviklingen som kjennes fra taswir-diskusjonene der de mange tekstfortolkningene differensierer bruken av bilder, og der få røster krever ubetinget forbud mot figurative bilder (Brekketo, 2014).

\section{KONKLUDERENDE BEMERKNINGER}

I samtalene har ungdommene vært opptatt av hjemmets innredning. De religiøse bildene har i alles bevissthet en selvfølgelig forrang fremfor andre bilder. De religiøse bildenes plassering får dermed konsekvenser for hvordan de verdslige bildene henges opp. Mye dreier seg om plasseringer og posisjoner, og det er et viktig poeng at disposisjonene gjøres synlige og forståelige for beboerne selv og for bes $\varnothing$ kende. Plasseringen av bilder gir signaler om livssyn og religi øs orientering. Derfor fører uenigheter om antropomorfe bilder til høy temperatur i meningsutvekslingene i noen familier. Det strides om intern kontroll, og om hvordan familien som helhet skal uttrykke religiøse holdninger overfor omverdenen. Disse uoverensstemmelsene om bilders prinsipielle sider og signaleffekt berører både sosialisering og opplæring i familiene.

Ungdommene forteller at de har lært å respektere de religiøse bildene som del av det hellige i religionen. Opplæringen har gått over lang tid, og er nedfelt i kroppslig atferd. Ingen av ungdommene stiller seg negative til denne opplæringen. Ikke alle er like engasjerte i religiøse spørsmål, men de opplever det som grunnleggende nødvendig å respektere det hellige. Det som er interessant å merke seg, er at opplæringen ikke har hatt samme effekt når det gjelder holdningene til verdslige antropomorfe bilder. I de familiene der det råder uenighet om slike bilder, har besteforeldre og foreldre fors $\varnothing \mathrm{kt}$ å videreformidle motforestillinger, men disse betenkelighetene har ikke hatt full gjennomslagskraft hos de unge. Når ungdommene forteller om familiemedlemmers motforestillinger mot verdslige antropomorfe bilder, er det tydelig at flere av dem føler avstand til det de forteller om. Dette er en distanse de ikke gir uttrykk for når de forteller om hvordan de selv og familien forholder seg til religiøse bilder.

Man kan tenke seg ulike grunner til at opplæringen har hatt mindre effekt når det gjelder verdslige antropomorfe bilder enn når det gjelder religiøse bilder. Ungdommene har lagt merke til at det finnes ulike holdninger til antropomorfe bilder innenfor de sunni-muslimske miljøene, og i noen tilfeller erfarer de ulike meninger i sitt eget hjem. Et annet viktig moment er at de religiøse synspunktene på verdslige antropomorfe bilder ikke blir stående uimotsagte når ungdommene beveger seg ut i det norske storsamfunnet. Som barn går de mange år i norsk grunnskole der figurative fremstillinger inngår som naturlige innslag i mange fag. Videre knytter ungdommene vennskap på tvers av ulike miljøer og erfarer dermed at det finnes forskjellige holdninger til antropomorfe bilder. Mange er også aktive på sosiale medier der fotografi er en sentral uttrykksform. Holdningene til verdslige antropomorfe bilder blir dermed ikke internaliserte og naturliggjorte på samme måte som holdningene til de religiøse bildene. Ungdommene erfarer tvert imot at holdningene til disse bildene er omdiskuterte, og derfor bringes spørsmål om disse bildene opp som emne for de unges egne refleksive oppmerksomhet. Ungdommene blir nødt til å holde ulike kunnskaper opp mot hverandre, reflektere og forme sitt eget personlige syn på slike bilder. Konsekvensene blir at ungdommenes holdninger utvikler seg i nye retninger.

Det er rimelig å tolke meningsbrytningene i familiene som uttrykk for generasjonsskiller, ulike oppvekstvilkår og ulik religiøs orientering. Ungdommene virker trygge på egne responsmønstre når de står overfor verdslige antropomorfe bilder. Ingenting tyder på at de vil videreføre kjønnssegregerende bildeplassering, eller at de vil gjemme portrettfotografier bort i album. De opplever ikke at

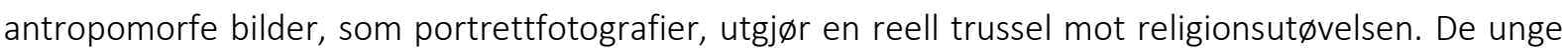
fremholder likevel at de vil opprettholde skillet mellom verdslige og religiøse bilder i sine fremtidige hjem. De åpner for et bredere utvalg av verdslige bilder i hjemmet enn det eldre generasjoner har gjort så lenge de mener at hensynet til religionen er godt nok ivaretatt. 
Birte BREKKETO - Bilder i hjemmet - hvordan visuelle uttrykk definerer muslimske rom i Norge

Ungdommenes beretninger om hvordan religiøse og verdslige bilder henges opp på veggene, gir innsikt i hvordan familiene definerer, og, ikke minst, redefinerer sine muslimske rom i møte med det sekulariserte norske samfunnet. 


\section{LITTERATUR}

Al-Qaradawi, Y. (2003). The Lawful and the Prohibited in Islam. Elfarouq Foundation. (Opprinnelig utgitt 1960)

Bal, M. (2003). Visual Essentialism and the Object of Visual Culture. Journal of Visual Culture 2(1), 5-33. https://doi.org/10.1177/147041290300200101

Bourdieu, P. (1995). Distinksjonen. En sosiologisk kritikk av dømmekraften. Pax.

Brekketo, B. (2013). Taswir i norsk kontekst. En undersøkelse av hvordan unge norskpakistanske muslimer forholder seg til visuell kommunikasjon med figurative uttrykk. (Doktoravhandling). Universitetet i Bergen.

Brekketo, B. (2014). Taswir - perspektiver frå en meningsutveksling om figurativ fremstilling i sunni-islam. FormAkademisk - Forskningstidsskrift for design og designdidaktikk, 7(5), 1-19. https://doi.org/10.7577/formakademisk.899

Didi-Huberman, G. (2005). Confronting Images: Questioning the Ends of a Certain History of Art. The Pennsylvania State University Press.

Elkins, J. (2007). Art History as a Global Discipline. I J. Elkins (Ed.), Is Art History Global? (pp. 3-24). Routledge.

Freedberg, D. (1989). The Power of Images: Studies in the History and Theory of Response. The University of Chicago Press. https://doi.org/10.7208/chicago/9780226259031.001.0001

Gell, A. (1998). Art and Agency: An Anthropological Theory. Clarendon Press.

Giddens, A. (1997). Modernitet og selvidentitet. Selvet og samfundet under senmoderniteten. Hans Reitzels Forlag.

Grabar, O. (2005). Early Islamic Art, 650-1100: Constructing the Study of Islamic Art. Ashgate Publishing Company.

Grabar, O. (2006). Islamic Art and Beyond. Ashgate Publishing Company.

Gruber, C. (2009). Between Logos (Kalima) and Light (Nür): Representations of the Prophet Muhammad in Islamic Painting. Muqarnas: An Annual on the Visual Cultures of the Islamic World, 26(1), 229-263. https://doi.org/10.1163/22118993_02601011

Jacobsen, C. M. (2006). Staying on the Straight Path: Religious Identities and Practices among Young Muslims in Norway. (Doktoravhandling). Universitetet i Bergen.

Kesner, L. (2007). Is a Truly Global History Possible? I J. Elkins (Ed.), Is Art History Global? (pp. 81-112). Routledge.

Merleau-Ponty, M. (1986). Phenomenology of Perception. Routledge \& Kegan Paul. (Opprinnelig publisert 1962)

Mirza, Y. (2005). Abraham as an Iconoclast: Understanding the Destruction of 'Images' through Qur'anic Exegesis. Islam and Christian-Muslim Relations 16(4), 413-428. https://doi.org/10.1080/09596410500250222

Mitchell, W. J. T. (2003). The Obscure Object of Visual Culture. Responses to Mieke Bal's 'Visual Essentialism and the Object of Visual Culture'. Journal of Visual Culture 2(2), 249-253. https://doi.org/10.1177/14704129030022010

Mitchell, W. J. T. (2008 [1995]). What is Visual Culture? In J. Morra \& M. Smith (Eds.), What is Visual Culture Studies? (bind 1, pp. 298-312). Routledge.

Morgan, D. 2005. The Sacred Gaze: Religious Visual Culture in Theory and Practice. University of California Press. https://doi.org/10.1525/9780520938304

Moxey, K. (2008). Visual Studies and the Iconic Turn. Journal of Visual Culture 7(2), 132-143. https://doi.org/10.1177/1470412908091934

Naguib, S.-A. (2002). The Northern Way: Muslim Communities in Norway. I Y. Y. Haddad \& J. I. Smith (Eds.), Muslim Minorities in the West: Visible and Invisible (pp. 161-175). Altamira Press.

Østberg, S. (2003). Muslim i Norge. Universitetsforlaget.

Qureshi, R. B. (1996). Transcending Space: Recitation and Community among South Asian Muslims in Canada. I B. D. Metcalf (Ed.), Making Muslim Space in North America and Europe (pp. 46-65). University of California Press. https://doi.org/10.1525/9780520917439-006 
Ramadan, T. (2004 [1999]). At være europæisk muslim: Islamske kilder i en europæisk sammenheng. Forlaget Hovedland.

Rogan, B. \& Naguib S.-A. (2011). Materiell kultur og forskning på tvers. En introduksjon. I S.-A. Naguib \& B. Rogan (Red.), Materiell kultur \& kulturens materialitet (ss. 9-19). Novus Forlag.

Rolness, K. (1995). Med smak skal hjemmet bygges. Aschehoug.

Shakir, A. M. A.-R. (1998). The Islamic Ruling Concerning At-Tasweer. Zakee Muwwakkil's Books \& Articles.

Thorbjørnsrud, B. (2004). Motstand mot slør/motstand med slør. I N. Høstmælingen (Red.), Hijab i Norge (ss. 36 52). Abstrakt forlag.

Vogt, K. (2004). Historien om et hodeplagg. I N. Høstmælingen (Red.), Hijab i Norge (ss. 23-36). Abstrakt forlag.

Ziehe, T. (1989). Kulturanalyser. Ungdom, utbildning, modernitet. Symposion Forlag.

Aase, T. H. (1997). Tolkning av kategorier. Observasjon, begrep og kategori. I E. Fossåskaret, O. L. Fuglestad \& T. H. Aase (Reds.), Metodisk feltarbeid: Produksjon og tolkning av kvalitative data (ss. 143-167). Universitetsforlaget. 